\title{
A new definition for wide-necked cerebral aneurysms
}

\author{
Hyun Seok Park', Soon Chan Kwon², Eun Suk Park ${ }^{2}$, Jun Bum Park ${ }^{2}$, Min Soo Kim² \\ ${ }^{7}$ Department of Neurosurgery, Dong Kang Medical Center, Ulsan, Korea, \\ ${ }^{2}$ Department of Neurosurgery, Ulsan University Hospital, University of Ulsan College of Medicine, Ulsan, Korea
}

Background : Endovascular management of wide-necked aneurysms often requires assisted-techniques with adjunctive devices. Wide-necked aneurysm can be defined with a dome-to-neck ratio or aspect ratio; however, clinical definitions of wide-necked aneurysms vary. This study aimed to determine the most useful definition of wide-necked aneurysm to predict the need for an adjunctive device.

Methods : Among 552 cases of aneurysms, 343 (62.1\%) and 209 (37.9\%) cases of unruptured and ruptured aneurysms, respectively, were treated in a single institution. For each aneurysm, the (1) dome-to-neck ratio, (2) aspect ratio, and (3) K-ratio (defined as [dome height + maximum dome width]/[2×maximum neck width]) were measured. We statistically analyzed patient data to determine which of the three ratios was most predictive of the need for adjunctive devices.

Results : Among 552 cases of aneurysms, 277 (50.2\%) and 275 (49.8\%) cases were treated with and without adjunctive techniques, respectively. The mean dome-to-neck ratio, aspect ratio, and K-ratio were $1.17 \pm 0.39,1.58 \pm 0.61$, and $1.37 \pm 0.47$, respectively. The K-ratio was the strongest predictor of the use of adjunctive devices $(\mathrm{P}<0.001)$, and 1.3 was the most appropriate K-ratio cut-off value (sensitivity, $72.9 \%$; specificity, $63.6 \%$ ).

Conclusions : K-ratio was the most useful predictor of the need for adjunctive devices in the treatment of endovascular aneurysms. These results suggest that the K-ratio may be used to define wide-necked aneurysms requiring complicated management via adjunctive devices.

\author{
$J$ Cerebrovasc Endovasc Neurosurg. \\ 2019 December;21(4):193-198 \\ Received : 5 September 2018 \\ Revised : 6 January 2020 \\ Accepted : 10 January 2020
}

\section{Correspondence to Soon Chan Kwon}

Department of Neurosurgery, Ulsan University Hospital, University of Ulsan College of Medicine, Ulsan, Korea

Tel : + 082-52-250-7139

E-mail : nskwon.sc@gmail.com

ORCID : http://orcid.org/0000-0003-4885-1456

Keywords Intracranial aneurysm, Endovascular treatment, Wide-necked aneurysm, Definition

This is an Open Access article distributed under the terms of the Creative Commons Attribution NonCommercial License (http://creativecommons.org/ licenses/by-nc/3.0) which permits unrestricted noncommercial use, distribution, and reproduction in any medium, provided the original work is properly cited.

\section{INTRODUCTION}

The standard treatment for cerebral aneurysms is endovascular repair. However, the treatment of widenecked aneurysms still presents challenges owing to the risks of coil protrusion into the parent artery and recurrence. ${ }^{4) 13)}$ Endovascular embolization of these widenecked aneurysms increases the frequency and necessity of techniques involving adjunctive devices such as stents and balloons. ${ }^{3(5)(6) 899) 12}$ Therefore, when planning the treatment of wide-necked aneurysms, preparations such as premedication and peri-aneurysmal vascular profiling are required for the smooth use of adjunctive devices and the prevention of procedure-related complications. ${ }^{114)}$ However, wide-necked aneurysms have been defined using many indices, such as neck width, dome-to-neck ratio, and aspect ratio, which may result in confusion when used in clinical practice. Therefore, 
to predict whether assisted techniques are required, another index for wide-necked aneurysms is necessary. The aim of this study was to establish a practical definition of wide-necked aneurysm that can predict the use of adjunctive devices.

\section{MATERIALS AND METHODS}

\section{Patients and aneurysms}

Between January 2012 and December 2016, endovascular treatments with coil embolization were performed for 552 cerebral aneurysms in 526 patients in a single institution. After approval by the Institutional Review Board (IRB) of our institution (approval No. 2018001), medical records and radiologic images were retrospectively reviewed. Based on medical records, the aneurysms were divided into ruptured ( $\mathrm{n}=209,37.9 \%)$ or unruptured aneurysms ( $\mathrm{n}=343,62.1 \%)$. Based on radiologic imaging, the measurements and calculations of the morphology of the aneurysms were performed on two- or three-dimensional rotational angiography. Finally, the (1) dome-to-neck ratio (maximum dome width/maximum neck width) and (2) aspect ratio (dome height/maximum neck width) were calculated to measure the neck size of the aneurysms. We also calculated a new reference value, termed (3) K-ratio, ([dome height + maximum dome width] $/[2 \times$ maximum neck width]) in order to consider both the dome height and width of the aneurysm (Fig. 1).
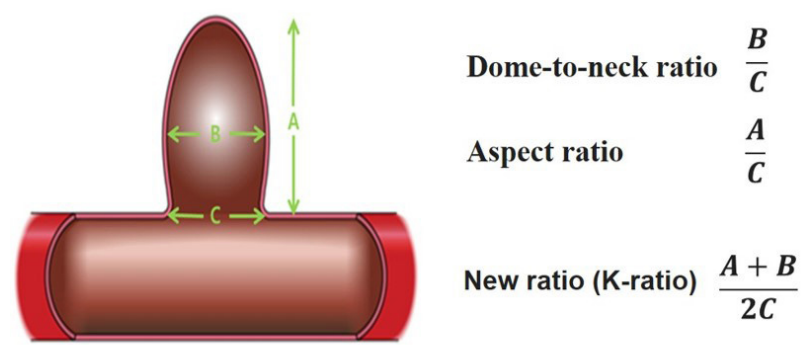
A: Dome height
B: Maximum dome width
C: Neck width

Fig. 1. Definitions of wide-necked cerebral aneurysm.

\section{Coiling procedures}

Patients with an unruptured aneurysm received antiplatelet premedication (100 mg aspirin and $75 \mathrm{mg}$ clopidogrel) each day for at least 7 days, and patients with a ruptured aneurysm received a loading dose of antiplatelet medication (100 mg aspirin and $300 \mathrm{mg}$ clopidogrel) immediately after the dome was covered with the coil. All procedures were performed by a single surgeon under general anesthesia with systemic intravenous heparinization. Activated clotting time was obtained at baseline and hourly thereafter. Four types of stents (Neuroform stent [Stryker Neurovascular, Kalamazoo, Michigan, USA], Enterprise stent [Codman \& Shurtleff, Raynham, Massachusetts, USA], Solitaire stent (Solitaire $\mathrm{AB}$ neurovascular remodeling device; Covidien, Irvine, California, USA), and Low-profile Visualized Intraluminal Support stent (MicroVention, Tustin, California, USA]) and three types of balloons (Scepter XC [MicroVention], Hyperform, and Hyperglide [ev3/Covidien]) were used. The use of an adjunctive device was either planned before the procedure, or applied when needed during the procedure.

\section{Radiographic and clinical outcomes}

Immediate occlusion results were graded using the Raymond grading system as complete occlusion (Grade I), residual neck (Grade II), and residual aneurysm (Grade III). ${ }^{13)}$ Procedure-related complications included thromboembolic infarction, aneurysm perforation, and parent artery dissection.

\section{Statistical analysis}

Statistical analysis was performed using SPSS software for Windows (version 19.0 [IBM Corp., Armonk, NY, USA]) and R package (version 3.2.5, R Foundation for Statistical Computing, Vienna, Austria). Continuous variables are expressed as the mean and standard deviation (SD), and categorical variables are expressed as the frequency and percentage.

Multivariable logistic regression with a forward stepwise method was used to calculate the odds ratio (OR) 
with 95\% confidence interval (CI). The threshold for statistical significance was set to $\mathrm{P}<0.05$.

Receiver operating characteristic (ROC) curves were used to determine the optimal cut-off values of (1) dome-to-neck ratio, (2) aspect ratio, and (3) K-ratio to predict the need for an adjunctive device. The pROC software package was used to draw ROC curves and to calculate the area under the curve (AUC) and 95\% CI. The Youden index was used to determine optimal cutoff values.

\section{RESULTS}

\section{Demographic and aneurysmal characteristics}

In total, 506 (91.7\%) and 46 aneurysms (8.3\%) arose from the anterior and posterior circulation, respectively. The mean aneurysmal height was $5.54 \pm 3.74 \mathrm{~mm}$ (range, $1.63-34.4 \mathrm{~mm}$ ), aneurysmal width was $4.10 \pm 2.88 \mathrm{~mm}$ (range, 1.3-27.7 mm), and the neck width was $3.68 \pm 1.68$ $\mathrm{mm}$ (range, $1.32-16.1 \mathrm{~mm}$ ).

\section{Angiographic and clinical outcomes}

All patients were treated successfully using a standard coiling technique. The initial angiographic results revealed that 424 (76.8\%), 90 (16.3\%), and 38 cases (6.9\%) had occlusions of Raymond grades I, II, and III, respectively.

There were 28 procedure-related complications (5.1\%). Thromboembolism with neurologic deficit was documented in 10 cases $(1.8 \%)$. Intraoperative aneurysm rupture occurred in $14(2.5 \%)$ cases, and all patients recovered without neurologic deficits. Dissection of the parent artery was observed in four cases (0.7\%).

\section{Relationship between ratio index and use of device}

In 275 (49.8\%) and 277 (50.2\%) cases of aneurysms, treatment proceeded with and without the use of an adjunctive device, respectively. Among the 277 cases that required an adjunctive device, stents were used in 245 cases (88.4\%), and balloons were used in 32 cases (11.6\%). In cases of ruptured and unruptured aneurysms, $40.2 \%$ $(29 / 69)$ and $73.9 \%(164 / 222)$ of the patients, respectively, were treated with an adjunctive device.

The mean values of the dome-to-neck ratio, aspect ratio, and K-ratio were $1.17 \pm 0.39,1.58 \pm 0.61$, and $1.37 \pm 0.47$, respectively. Along with the overall values, the mean values of these ratios for aneurysms treated with adjunctive devices and those treated without adjunctive devices are shown in Table 1. Only the K-ratio demonstrated a significant difference according to adjunctive device use $(\mathrm{P}<0.001)$. The optimal cut-off values of the dome-to-neck ratio, aspect ratio, and K-ratio obtained using the Youden index were 1.0, 1.4, and 1.3, respectively (Fig. 2).

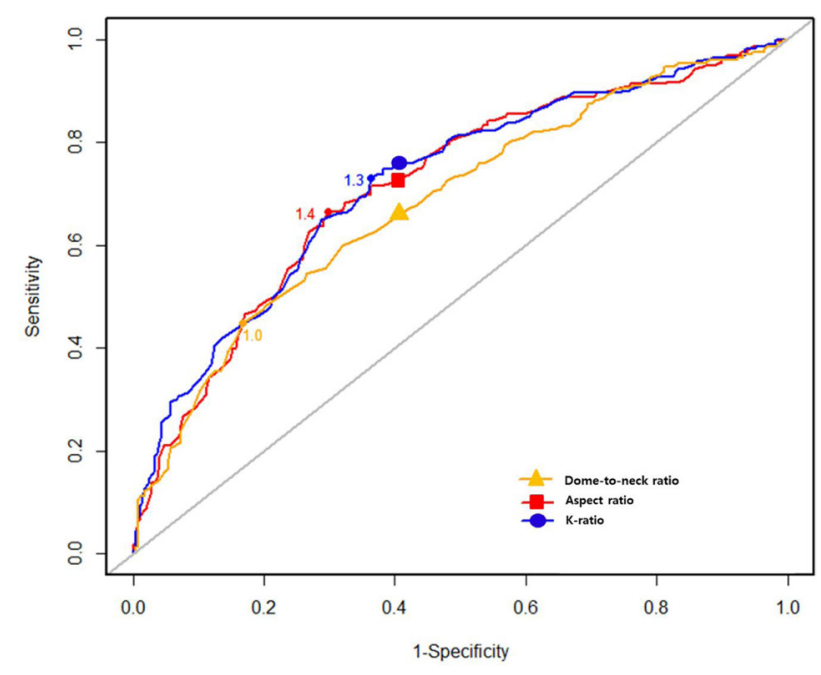

Fig. 2. Reference values of the dome-to-neck ratio (1.0), aspect ratio (1.4), and K-ratio (1.3).

Table 1. Relationship of index ratios with device usage

\begin{tabular}{lccc}
\hline & Total & \multicolumn{2}{c}{ Adjunctive device use } \\
\cline { 3 - 4 } & & Without & With \\
\hline Dome-to-neck ratio & $1.17 \pm 0.39$ & $1.27 \pm 0.40$ & $1.06 \pm 0.36$ \\
Aspect ratio & $1.58 \pm 0.61$ & $1.75 \pm 0.64$ & $1.40 \pm 0.53$ \\
K-ratio & $1.37 \pm 0.47$ & $1.52 \pm 0.49$ & 0.599 \\
\hline
\end{tabular}




\section{DISCUSSION}

Whether or not an aneurysm has a wide neck, is an important factor to determine the feasibility of endovascular treatment. The challenge of wide-necked aneurysms, which are difficult to treat by simply packing the coils into the aneurysm, can be overcome by the use of stents and balloons. In addition, when conducting coil embolization for the treatment of a wide-necked aneurysm, the catheter type, size, and puncture site should be planned in advance if the use of ancillary devices, such as stents and balloons, are being considered. Therefore, the present study investigated the index that was most reflective of the use of adjunctive devices for wide-necked aneurysms. Among them, we found that the K-ratio, which incorporates both the height and width of the aneurysm dome, was the most relevant index of wide-necked aneurysms. This finding suggests that the K-ratio is an appropriate indicator for judging wide-necked aneurysms. Based on virtual models of aneurysms (Figs. 3-4), the K-ratio appears to be more useful for identifying wide-necked aneurysms than the dome-to-neck ratio or aspect ratio.

We also calculated the appropriate reference value for this index to establish the most appropriate treatment strategy for wide-necked aneurysms, and the K-ratio cut-off value was set to 1.3 . For K-ratios $<1.3$, the sensitivity and specificity for the use of adjunctive devices were $72.9 \%$ and $63.6 \%$, respectively. The calculated cutoff values of the dome-to-neck ratio and aspect ratio were 1.0 and 1.4, respectively, and their sensitivities were low (dome-to-neck ratio, $44.8 \%$; aspect ratio, $66.4 \%)$.

Another important factor affecting the use of an adjunctive device was the presence of aneurysm rupture. Among aneurysms with a K-ratio $<1.3$, which indicates a wide neck, an adjunctive device was used in only $40.2 \%$ cases of ruptured aneurysms (29/69), whereas $73.9 \%$ cases of unruptured aneurysms $(164 / 222)$ were treated with an adjunctive device. This difference in the rate of adjunctive device use was statistically significant $(\mathrm{P}<0.001)$. We speculate that there are several reasons for this result: (1) increased risk of delaying surgery due to the necessity for anti-platelet agents prior to
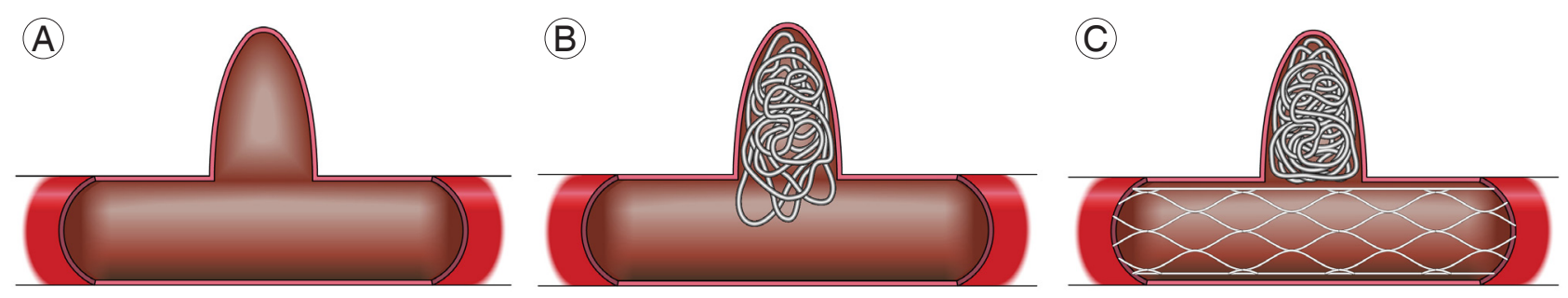

Fig. 3. In cases where the maximum dome width is the neck width (cone or rod shape), (A) treatment with the coil alone may not cover the aneurysm neck, or the coil is likely to protrude into the parent artery (B). In such cases, embolization with a stent will allow for successful treatment (C).

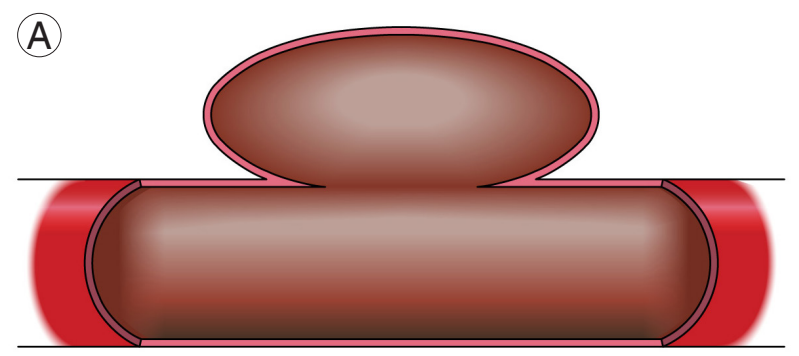

(B)

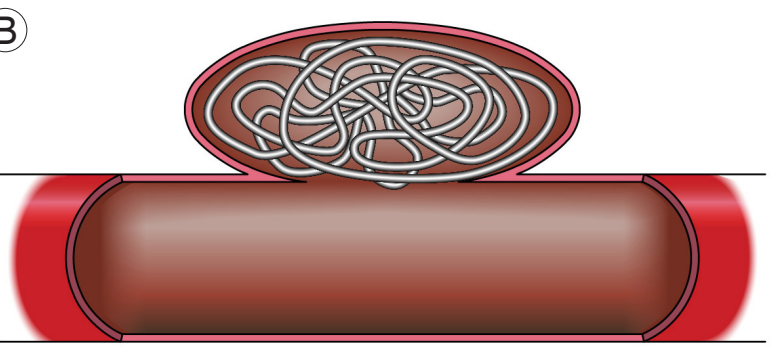

Fig. 4. If the height of the aneurysm dome is small (A) but the maximum width of the dome is sufficiently larger than the neck width, the coil alone can be used to complete the treatment (B). 
the use of an adjunctive device, (2) thromboembolic complication due to insufficient premedication, and (3) patient burden of prolonged general anesthesia. ${ }^{110) 11115)}$ In summary, in cases with a K-ratio $<1.3$, we found that adjunctive devices were used heavily when treating unruptured aneurysms with sufficient premedication.

Using a cut-off dome-to-neck ratio $<2,532$ (96.4\%) aneurysms were defined as wide-necked. Meanwhile, 230 (41.6\%) and 291 aneurysms (52.7\%) were classified as wide-necked when an aspect ratio $<1.6$ and K-ratio $<1.3$ were applied as the cut-off values, respectively, which was similar to the 277 (50.2\%) cases that required an adjunctive device. These results suggest that the definition of wide-necked aneurysm using the dometo-neck ratio may require reconsideration. Brinjikji et al. ${ }^{2)}$ proposed that a dome-to-neck ratio $<1.6$ should be used as the criterion for wide-necked aneurysms.

This study has several limitations. First, only patients treated by a single surgeon were analyzed to control for inconsistencies in criteria for adjunctive device use across operators. This is appropriate for comparing the relationship between the index ratios and device usage, but the cut-off values may differ according to the individual surgeon's preference for device use. Therefore, the new ratio should be verified in other patient populations. Second, we limited the reason for the use of adjunctive devices to the presence of a wide neck. Although in most cases, the neck width determines whether an adjunctive device is needed to preserve the parent artery, this excludes incidental causes such as aneurysm location, vascular status, parent artery, and dome orientation. ${ }^{7}$

\section{CONCLUSIONS}

In this retrospective study, we established a practical definition for wide-necked aneurysms by comparing the association of multiple indicators with the use of adjunctive devices in endovascular treatment. In the present population, the K-ratio ([dome height + maximum dome width] $/[2 \times$ maximum neck width $]$ ) was the most suitable definition of wide-necked aneurysm for predicting treatment with an adjunctive device. Especially for the management of unruptured aneurysms with a K-ratio $<1.3$, the use of an adjunctive device can provide a safe and reliable treatment.

\section{REFERENCES}

1. Bodily KD, Cloft HJ, Lanzino G, Fiorella DJ, White PM, Kallmes DF. Stent-assisted coiling in acutely ruptured intracranial aneurysms: a qualitative, systematic review of the literature. AJNR Am J Neuroradiol. 2011 Aug;32(7):1232-6.

2. Brinjikji W, Cloft HJ, Kallmes DF. Difficult aneurysms for endovascular treatment: overwide or undertall? AJNR Am J Neuroradiol. 2009 Sep;30(8):1513-7.

3. Chung J, Lim YC, Suh SH, Shim YS, Kim YB, Joo JY, et al. Stent-assisted coil embolization of ruptured wide-necked aneurysms in the acute period: incidence of and risk factors for periprocedural complications. J Neurosurg. 2014 Jul;121(1):411.

4. Cloft HJ, Joseph GJ, Tong FC, Goldstein JH, Dion JE. Use of three-dimensional Guglielmi detachable coils in the treatment of wide-necked cerebral aneurysms. AJNR Am J Neuroradiol. 2000 Aug;21(7):1312-4.

5. Fischer S, Weber A, Carolus A, Drescher F, Gotz F, Weber W. Coiling of wide-necked carotid artery aneurysms assisted by a temporary bridging device (Comaneci): preliminary experience. J Neurointerv Surg. 2017 Nov;9(11):1039-97.

6. Kitahara T, Hatano T, Hayase M, Hattori E, Miyakoshi A, Nakamura T. Jailed double-microcatheter technique following horizontal stenting for coil embolization of intracranial widenecked bifurcation aneurysms: a technical report of two cases. Interv Neuroradiol. 2017 Apr;23(2):117-22.

7. Kiyosue H, Tanoue S, Okahara M, Hori Y, Nakamura T, Nagatomi $\mathrm{H}$, et al. Anatomic features predictive of complete aneurysm occlusion can be determined with three-dimensional digital subtraction angiography. AJNR Am J Neuroradiol. 2002 Aug;23(7):1206-13.

8. Kuriyama T, Sakai N, Niida N, Sueoka M, Beppu M, Dahmani $\mathrm{C}$, et al. Dose reduction in cone-beam CT scanning for intracranial stent deployment before coil embolization of intracranial wide-neck aneurysms. Interv Neuroradiol. 2016 Aug;22(4):420-5.

9. Labeyrie PE, Gory B, Aguilar-Perez M, Pomero E, Biondi A, Riva $\mathrm{R}$, et al. The pCONus device for treatment of complex wide-neck anterior communicating artery aneurysms. World Neurosurg. 2017 May;101:498-505.

10. Lee YJ, Kim DJ, Suh SH, Lee SK, Kim J, Kim DI. Stent-assist- 
ed coil embolization of intracranial wide-necked aneurysms. Neuroradiology. 2005 Sep;47(9):680-9.

11. Lodi YM, Latorre JG, El-Zammar Z, Swarnkar A, Deshaies E, Fessler RD. Stent assisted coiling of the ruptured wide necked intracranial aneurysm. J Neurointerv Surg. 2012 Jul;4(4):281-6.

12. Peterson E, Hanak B, Morton R, Osbun JW, Levitt MR, Kim LJ. Are aneurysms treated with balloon-assisted coiling and stent-assisted coiling different? Morphological analysis of 113 unruptured wide-necked aneurysms treated with adjunctive devices. Neurosurgery. 2014 Aug;75(2):145-51; quiz 151.
13. Raymond J, Guilbert F, Weill A, Georganos SA, Juravsky L, Lambert A, et al. Long-term angiographic recurrences after selective endovascular treatment of aneurysms with detachable coils. Stroke. 2003 Jun;34(6):1398-403.

14. Shapiro M, Becske T, Sahlein D, Babb J, Nelson PK. Stent-supported aneurysm coiling: a literature survey of treatment and follow-up. AJNR Am J Neuroradiol. 2012 Jan;33(1):159-63.

15. Wang K, Sun Y, Li AM. Peri-procedural morbidity and mortality associated with stent-assisted coiling for intracranial aneurysms. Interv Neuroradiol. 2013 Mar;19(1):43-8. 